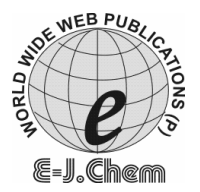

http://www.e-journals.net
CODEN ECJHAO

E-Journal of Chemistry

Vol. 3, No.2, pp 83-96, May 2006

\title{
Preparation and Utilization of Kapok Hull Carbon for the Removal of Rhodamine-B from Aqueous Solution
}

\author{
P.S.SYED SHABUDEEN ${ }^{1} *$ R.VENCKATESH ${ }^{2}$ and S.PATTABHI ${ }^{3}$ \\ ${ }^{1}$ Department of Chemistry, Kumaraguru College of Technology, Coimbatore - 641006 , \\ ${ }^{2}$ Department of Chemistry, Karpagam College of Engineering, Coimbatore - 641032 , \\ ${ }^{3}$ Department of Environmental Science, PSG College of Arts and Science, \\ Coimbatore - 641 014, India
}

Received 20 February 2006; Accepted 14 April 2006

\begin{abstract}
A carbonaceous sorbent prepared from the indegeneous agricultural waste (which is facing solid waste disposal problem) Kapok Hull, by acid treatment was tested for its efficiency in removing basic dyes. Batch kinetic and isotherm experiments were conducted to determine the sorption and desorption of the Rhodamine-B from aqueous solution with activated carbon. The factors affecting the rate processes involved in the removal of dye for initial dye concentration, agitation time, and carbon dose and particle size have been studied at ambient temperature. The adsorption process followed first order rate kinetics. The first-order rate equation by Lagergren was tested on the kinetic data, and isotherm data was analyzed for possible agreement with the Langmuir and Freundlich adsorption isotherm equations. The intraparticle diffusion rate equation from which adsorption rate constants, diffusion rate constants and diffusion coefficients were determined. Intraparticle diffusion was found to be the ratelimiting step. The structural and morphological of activated carbon were characterized by XRD and SEM studies respectively.
\end{abstract}

Key words: Activated carbon, Adsorption, Particle Size, X-ray diffraction, Scanning, Electron Microscope,

\section{Introduction}

Urbanization and industrialization are making a heavy demand for water resource. This resource needs to be conserved and the industrial effluent is to be recycled. Therefore the concept of reuse, recycle and reduce have been very well conceived by industries, efforts in 
this direction need to be accelerated. So far, there is no viable technology available to treat the textile effluents and the sludge. A suitable technology with zero generation of sludge will therefore help to contain the problem of sludge disposal. The present study is envisaged to develop a cost effective method of treatment of textile dye by using a solid agriculture waste, which is facing solid waste disposal problem is effectively and efficiently converted into an activated carbon and it is utilized to study the effectiveness of the removal of color from textile effluents. The color removal from textile effluent was attempted ${ }^{1}$ and the wastewater management studies were planned and executed ${ }^{2}$. Industrial wastewater treatment from manufacturing chemical industries was analysed ${ }^{3}$ and the chemical properties of synthetic process ${ }^{4}$ and methodologies were formulated ${ }^{5}$. Decolorizing dye with chlorine and ozone was developed ${ }^{6-9}$.

The conventional method for the removal of dyes using alum, ferric chloride, activated carbon, lime, etc., is not economical in the Indian context. The low cost conventional adsorbent for the treatment of industrial wastewater had been reviewed Polard et al., ${ }^{10}$. Some works of low cost, non-conventional adsorbents has been carried out. Adsorbents used include agricultural solid wastes such as saw dust ${ }^{11}$, peat mass and rice hulls ${ }^{12}$, coconut husk ${ }^{13}$, industrial solid wastes such as fly-ash from coal-burning industries ${ }^{14}$ and $\mathrm{Fe}(\mathrm{III}) / \mathrm{Cr}$ (III) hydroxide ${ }^{15}$. A study on the use of wastes of biogas residual slurry and waste banana pith which is the effective removal of Congo red, Rhodamine-B and acid violet ${ }^{16,17}$ bagasse and paddy straw ${ }^{18}$, coir pith ${ }^{19}$. Non-conventional material like chitosan ${ }^{20}$, chitosan fibre, thermal power waste ${ }^{21}$, red mud ${ }^{22}$, Silica fomes ${ }^{23}$, Eucalyptus bark ${ }^{24}$, Carbon from cassava peels ${ }^{25}$. Activated carbon from Jackfruit peel ${ }^{26}$, activated Parthenium ${ }^{27}$ palm nut shells, cashew nut shells and Broom sticks ${ }^{28}$, Flyash ${ }^{29}$, saw dust ${ }^{30}$, Coffee grounds ${ }^{31}$ and pine saw dust ${ }^{32}$.

The objective of the present study is to prepare and characterize quality and evaluate the efficiency of using Kapok hull carbon as an adsorbent for the removal of dye like Rhodamine-B. However in the present study Rhodamine-B has been subjected for color removal using KHAC. After considering the efficiency of color removal, the study was extended for other adsorbate and such study has not been attempted earlier. The adsorption study was carried out systematically involving various parameters such as agitation time, initial concentration, adsorbent dose, desorption, $\mathrm{pH}$ and temperature. The data generated over this study have been tabulated and discussed. The cost of this activated carbon is estimated and which is 10 times less than that of commercially available activated carbons.

\section{Experimental}

The kapok hull was cut into small pieces, dried in sunlight, then $60^{\circ} \mathrm{C}$ for 24 hours in hot air oven. The dried material is subjected for acid treatment (ratio 1:1) and kept at room temperature overnight. Then it was washed with doubled distilled water to remove the excess acid and kept in hot air oven at $110^{\circ} \mathrm{C}$ for 12 hours. Then it was taken in an iron vessel in muffle furnace and the temperature was gradually raised to $550^{\circ} \mathrm{C}$ for an hour, ground well by using ball mill and then sieved into particle size of 250,150 and 100 BSS mesh numbers. The preparation of stock solution of dye for $1000 \mathrm{ppm}$ by using double distilled water. These dye solutions were taken for adsorption studies with KHAC. The characterization of KHAC was carried out and the results were tabulated in Table 1.

The adsorbent KHAC sieved particle size of 250BSS mesh number was magnified by Scanning Electron Microscope (SEM) studies by using JOEL JSM 8404 Scanning microscope as shown in the Figure 1. The X-ray Diffraction studies of KHAC were carried 
out using Rotoflux X-ray Diffractometer 20KW/20A, Model 10.61 with a Microprocessor recorder. The XRD pattern of the KHAC is shown in the Figure 2. The morphological and XRD studies clearly revealed that the adsorbent is amorphous and highly porous in nature. From the SEM analysis it was found that there were holes and cave type openings on the surface of the adsorbent, which would have more surface area available for adsorption ${ }^{33}$.

Table 1. Characteristic of KHAC

\begin{tabular}{|c|c|c|}
\hline S.No & Parameters & Obtained Result \\
\hline 1. & pH solution & 6.7 \\
\hline 2. & Moisture content (\%) & 2.4 \\
\hline 3. & Ash content $(\%)$ & 1.856 \\
\hline 4. & Decolorizing power $(\mathrm{mg} / \mathrm{g})$ & 22.5 \\
\hline 5. & $\begin{array}{l}\text { Ion-exchange capacity } \\
\text { (milliequi/g) }\end{array}$ & 0.0415 \\
\hline 6. & Surface area $\left(\mathrm{m}^{2} / \mathrm{g}\right)$ & $158-228$ \\
\hline 7. & Apparent Density (g/l) & 0.42 \\
\hline 8. & Particle size $(\mu \mathrm{m})$ & 125 \\
\hline 9. & Volatile matter $(\%)$ & 12.0 \\
\hline 10. & Fixed carbon $(\%)$ & 86.0 \\
\hline 11. & Calcium $(\%)$ & 16.0 \\
\hline 12. & Sodium (mg/g) & 7.0 \\
\hline 13. & Potassium $(\mathrm{mg} / \mathrm{g})$ & 13.0 \\
\hline 14. & Water soluble matter $(\%)$ & 2.0 \\
\hline 15 & $\mathrm{HCl}$ soluble matter $(0.25 \mathrm{~N})(\%)$ & 7.0 \\
\hline 16. & Phenol number, mg & 11.2 \\
\hline
\end{tabular}

Table 2 Effect of adsorbent dosage and particle size on the removal of Rhodamine-B (100mg/l) at 300K

\begin{tabular}{cccccccccc}
\hline \multirow{2}{*}{$\begin{array}{c}\text { Carbon } \\
\text { Dose }\end{array}$} & \multicolumn{3}{c}{$\%$ Removal } & \multicolumn{3}{c}{$\log$ X/M } & \multicolumn{3}{c}{$\log \mathrm{Ce}$} \\
\cline { 2 - 10 } & 250 & 150 & 100 & 250 & 150 & 100 & 250 & 150 & 100 \\
\hline 100 & 57 & 43 & 35 & -2.244 & -2.367 & -2.456 & -0.367 & -0.244 & -0.187 \\
200 & 68 & 46 & 51 & -2.469 & -2.638 & -2.593 & -0.495 & -0.268 & -0.31 \\
300 & 83 & 56 & 58 & -2.558 & -2.729 & -2.714 & -0.77 & -0.357 & -0.377 \\
400 & 88 & 71 & 70 & -2.658 & -2.751 & -2.757 & -0.921 & -0.538 & -0.523 \\
500 & 97 & 85 & 89 & -2.712 & -2.77 & -2.75 & -1.523 & -0.824 & -0.959 \\
600 & 100 & 95 & 95 & -3.041 & -2.8 & -2.8 & - & -1.301 & -1.301 \\
700 & 100 & 100 & 100 & -3.041 & -2.401 & -2.401 & - & - & - \\
\hline
\end{tabular}

The Freundlich and Langmuir isotherm studies and Lagergran kinetic studies at ambient temperature, dye solution of various concentrations was agitated with $1 \mathrm{~g}$ of the adsorbent of 250,150 and 100BSS mesh number particle size over a period of time with constant stirring at constant $\mathrm{pH}$ (6.4). The carbon dosage of $100 \mathrm{mg}$ to $1000 \mathrm{mg}$ was agitated with a known concentration of dye solution. 

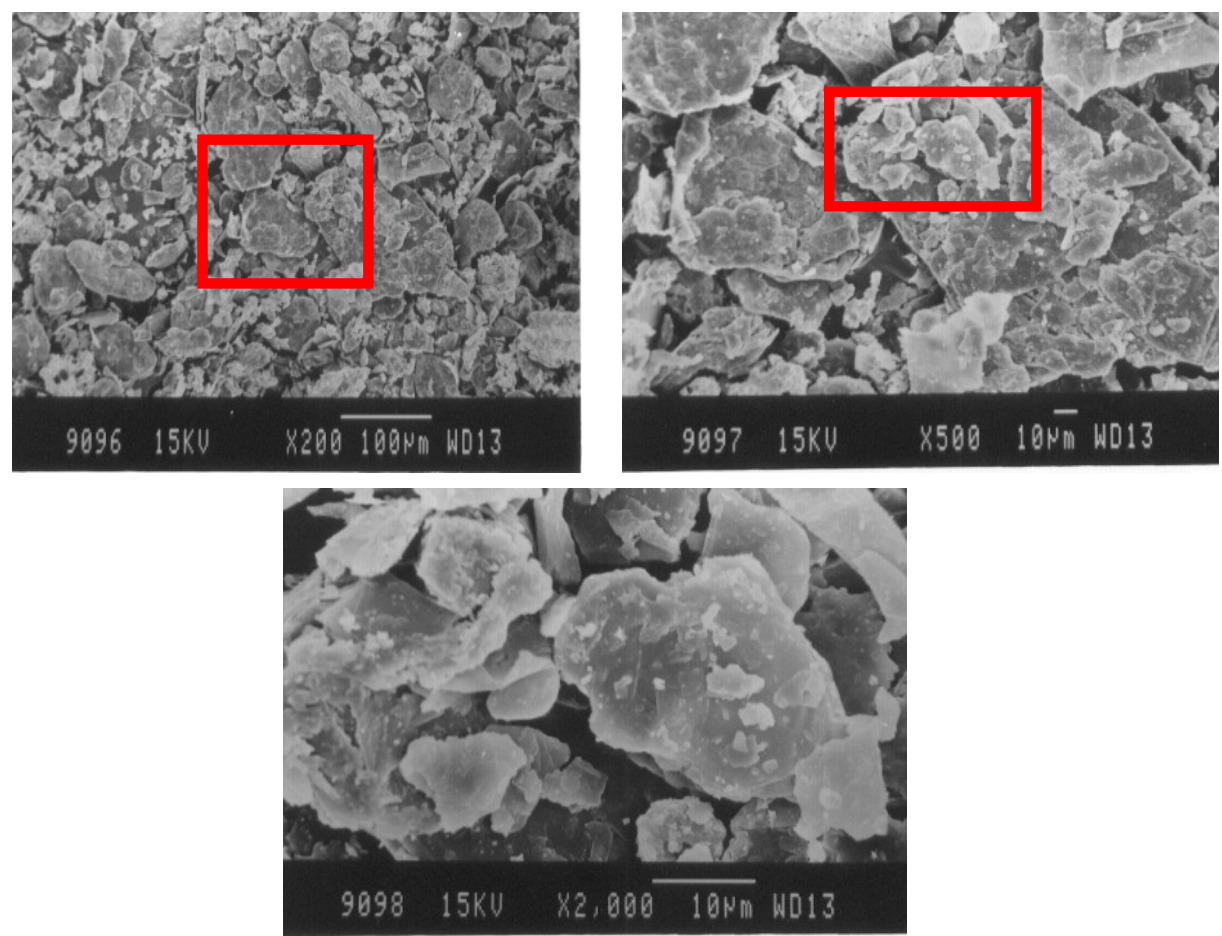

Figure 1. SEM photograph of Kapok Hull Activated Carbon (KHAC) at various magnifications (x200, x500 and x2000)

The exhausted activated carbon was used for desorption studies. The carbon loaded with dye was separated and gently washed with distilled water to remove any unadsorbed dyes. The dye-laden carbons were agitated with $100 \mathrm{~mL}$ of neutral $\mathrm{pH}$ water, $1 \mathrm{M}$ sulpuric acid, $1 \mathrm{M}$ sodium hydroxide, $10 \%$ acetic acid (v/v) and $50 \%$ acetic acid (v/v) separately for $60 \mathrm{~min}$.

\section{Results and Discussion}

\section{Langmuir Adsorption Isotherm}

Langmuir adsorption isotherm is based on the assumption that, "Adsorption is a type of chemical combination in which adsorbate is adsorbed on the adsorbent surface and the adsorbed layer is unimolecular".

Langmuir represented the following equation, $\mathrm{q}_{\mathrm{e}}=\left(\mathrm{Q}_{0} \times \mathrm{b} \times \mathrm{C}_{\mathrm{e}}\right) /\left(1+\left(\mathrm{b} \times \mathrm{C}_{\mathrm{e}}\right)\right)$, where, $\mathrm{q}_{\mathrm{e}}$ is equal to the quantity of dye adsorbed in $\mathrm{mg} / \mathrm{g}$ of the adsorbent, $\mathrm{Q}_{0}$ is the maximum quantity of dye adsorbed in $\mathrm{mg} / \mathrm{gram}$ of the adsorbent, $\mathrm{b}$ and $\mathrm{C}_{\mathrm{e}}$ is the constant of Langmuir adsorption and the dye concentration at equilibrium in $\mathrm{mg} / \mathrm{l}$ respectively. Langmuir adsorption parameters are determined by transforming the equation, which is in linear form. The Linear plot of $\mathrm{C}_{\mathrm{e}} / \mathrm{q}_{\mathrm{e}} \mathrm{Vs} \mathrm{C}_{\mathrm{e}}$ showed that the adsorption followed Langmuir isotherm model as shown in Figures 3-5. The values of monolayer capacity ' $\mathrm{Q}_{0}$ ' and Langmuir constant ' $b$ ' had been evaluated from the intercept and slope of these plots by using graphical techniques. 


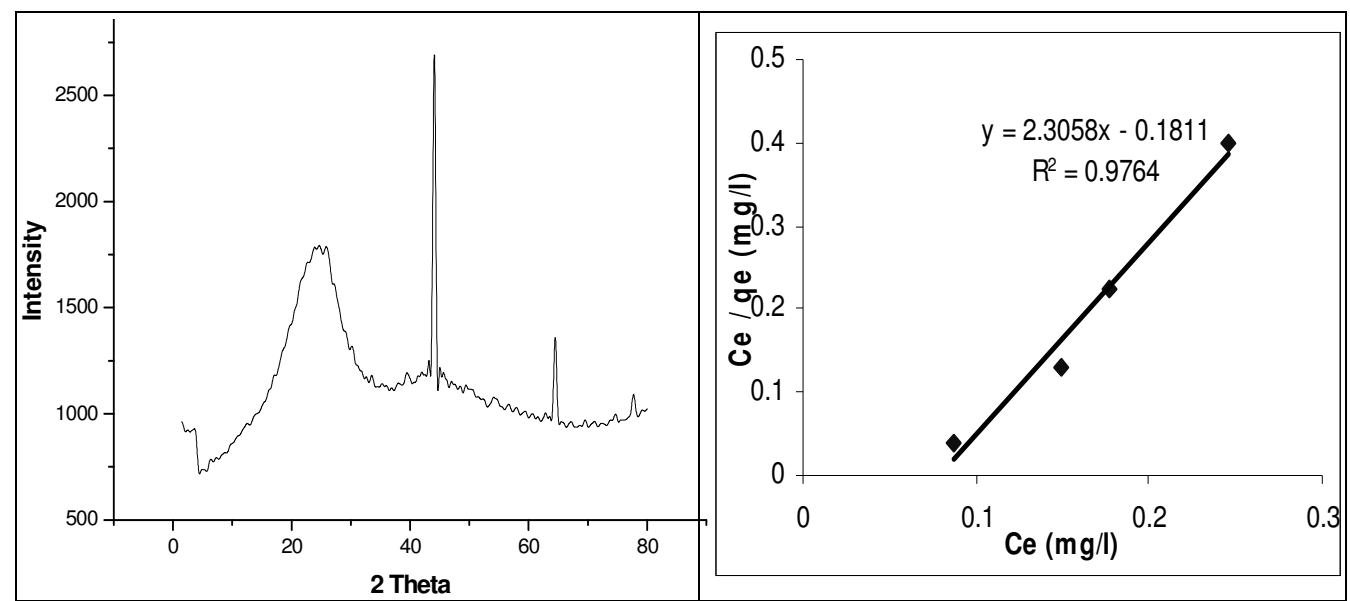

Figure 2. X-ray Diffraction pattern for KHAC

Figure 3. Langmuir adsorption isotherm of

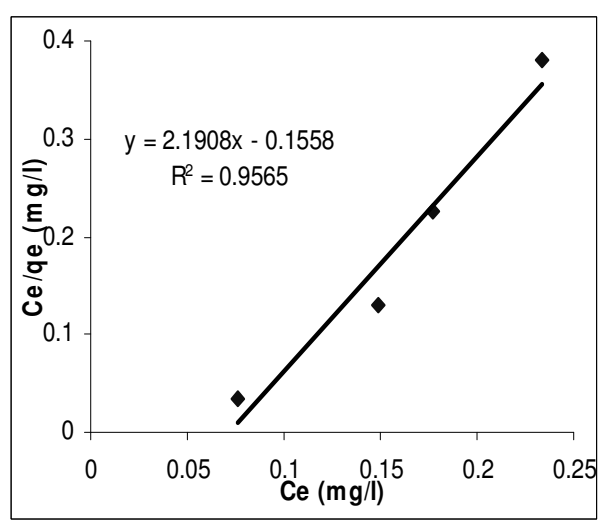

Figure 4. Langmuir adsorption isotherm of Rhodamine-B for 150BSS particle size at $300 \mathrm{~K}$
Rhodamine-B for 100BSS particle size at $300 \mathrm{~K}$

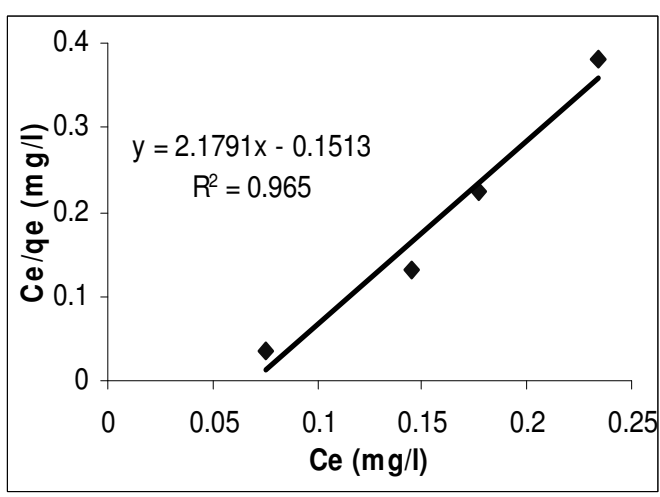

Figure 5. Langmuir adsorption isotherm of Rhodamine-B for 250BSS particle size at $300 \mathrm{~K}$

The effect of isotherm shape has been taken into consideration with a view to predict whether the studied adsorption system is favorable or unfavorable. The essential features of the Langmuir isotherm may be expressed in terms of equilibrium parameter $\mathrm{R}_{\mathrm{L}}$, which is a dimension less constant referred to as separation factor or equilibrium parameter ${ }^{34}$. $\mathrm{R}_{\mathrm{L}}=1 /\left(1+\mathrm{bC}_{0}\right)$, where $\mathrm{C}_{0}$ is the initial concentration and ' $\mathrm{b}$ ' is the constant related to the energy of adsorption (Langmuir Constant). The values of $\mathrm{R}_{\mathrm{L}}$ indicate the nature of the isotherm, if the conditions are $\mathrm{R}_{\mathrm{L}}>1, \mathrm{R}_{\mathrm{L}}=1,0<\mathrm{R}_{\mathrm{L}}<1$ and $\mathrm{R}_{\mathrm{L}}=0$ are unfavorable, linear, favorable and irreversible respectively. The value of $R_{L}$ was less than one which showed that the adsorption process was favorable. 


\section{Effect of Temperature}

The adsorption study was carried out for Rhodamine-B at ambient temperature. This was mainly due to the increase in pore volume. It may be due to the adsorption increases with increase in temperature and pores volume.

Further, the results were analysed and found that the adsorption process was endothermic and best fitted to Langmuir adsorption isotherm model. By employing graphical and mathematical methodologies, the $\mathrm{Q}_{0}, \mathrm{~b}$ and $\mathrm{R}_{\mathrm{L}}$ values for different particle size for the dye was evolved and it was revealed that $\mathrm{R}_{\mathrm{L}}$ values lay between 0 and 1 . It was inferred that the adsorption process followed Langmuir model and favorable for adsorption.

The free energy change $\left(\Delta \mathrm{G}^{\circ}\right)$, enthalpy change or total energy change $\left(\Delta \mathrm{H}^{\circ}\right)$ and entropy change $\left(\Delta \mathrm{S}^{\circ}\right)$ values were evolved by utilizing mathematical tools and adopting the following thermodynamic formulae,

Free energy change, $\Delta \mathrm{G}^{\circ}=-\mathrm{RT} \ln \mathrm{b}$

Enthalpy change or total energy change $\left(\Delta \mathrm{H}^{\circ}\right)$ can be calculated by using the thermodynamics formula, $\ln \left[\mathrm{b}_{1} / \mathrm{b}_{2}\right]=\Delta \mathrm{H}^{\circ} / \mathrm{RT}$

The Gibbs free energy change is, $\Delta \mathrm{G}^{\circ}=\left[\Delta \mathrm{H}^{\circ}-\Delta \mathrm{S}^{\circ}\right] / \mathrm{T}$

The results of $\Delta \mathrm{G}^{\circ}, \Delta \mathrm{H}^{\circ}$ and $\Delta \mathrm{S}^{\circ}$ were summarized in the Table 5. The positive values of $\Delta \mathrm{H}^{\circ}$ indicate that the adsorption is involved with weak forces of attraction. It was observed that the $\Delta \mathrm{H}^{\circ}$ values increased with decrease of particle size. The adsorption was found to be endothermic in nature. The positive and increased $\Delta S^{\circ}$ values for smaller particle size indicated that the KHAC showed greater affinity towards the dye. Further, the negative $\Delta \mathrm{G}^{\circ}$ value indicated the spontaneous nature of the adsorption model.

For unimolecular reactions, the energy of activation was evolved by using the following equation, $\mathrm{E}_{\mathrm{a}}=\Delta \mathrm{H}^{0}+\mathrm{RT}$

From the above it was observed that, the value of energy of activation for Rhodamine$\mathrm{B}$, the adsorption systems was less than $42 \mathrm{KJ} / \mathrm{mol}$. Then the process was confirmed to be diffusion controlled, or due to chemisorption. Suppose if in between 5 to $20 \mathrm{KJ} / \mathrm{mol}$, the sorption process was due to activated sorption, in our study of KHAC was in the range which is confirms the activated carbon. The carbon follows Langmuir adsorption isotherm, it had greater affinity towards the dye than carbon and the process was spontaneous. Similar pattern of results were inferred ${ }^{35,36}$.

\section{Freundlich Adsorption Isotherm}

The linear plot of $\log \mathrm{X} / \mathrm{m}$ Vs $\log \mathrm{C}_{\mathrm{e}}$ showed that the adsorption followed Freundlich adsorption isotherm model. The values of $\mathrm{X} / \mathrm{m}$ and $\mathrm{C}_{\mathrm{e}}$ observed from the adsorption experiments carried over by using KHAC of different particle sizes namely 100, 150 and 250BSS mesh numbers of constant mass was agitated with Rhodamine - B of known concentration at $300 \mathrm{k}$ to the respective equilibrium periods are presented in Table 4 . Based upon these experiments Freundlich adsorption isotherm plot was formed by plotting $\log \mathrm{X} / \mathrm{m}$ $\mathrm{Vs} \log \mathrm{C}_{\mathrm{e}}$ and it was presented in the Figure 6. The slope and intercept of this linear portion of isotherm plots were determined by adopting graphical methodology. These slope values had indicated adsorption intensity ' $n$ ' and the intercept values indicated an idea about adsorption capacity $\mathrm{K}_{\mathrm{F}}$. These values were tabulated (Table 3). It was observed that the adsorption capacity of the KHAC had increased with decrease of particle size at ambient temperature of the dye selected for the present study. 
The adsorption process, the surface energy $\mathrm{q}_{\mathrm{e}}$ is a function of heat, $\mathrm{K}_{\mathrm{F}}$ and $\mathrm{n}$ are adsorption constants are used to explained ${ }^{37}$. The Freundlich adsorption isotherm is as follows, $\mathrm{q}_{\mathrm{e}}=\mathrm{X} / \mathrm{m}=\mathrm{K}_{\mathrm{F}} \mathrm{C}_{\mathrm{e}}{ }^{1 / \mathrm{n}} ; \ln \mathrm{X} / \mathrm{m}=\ln \mathrm{q}_{\mathrm{e}}=\ln \mathrm{K}_{\mathrm{F}}+1 / \mathrm{n} \ln \mathrm{C}_{\mathrm{e}}$; where $\mathrm{q}_{\mathrm{e}}, \mathrm{C}_{\mathrm{e}}, \mathrm{X}$ and $\mathrm{M}$ are adsorbed amount on the adsorbent at equilibrium, equilibrium concentration of dye in solution ( $\mathrm{mg} / \mathrm{l})$, amount of dye adsorbed $(\mathrm{mg})$ and weight of the adsorbent used $(\mathrm{g})$. The constant $\mathrm{K}_{\mathrm{F}}$ represents the quantity of dye adsorbed in $\mathrm{mg} / \mathrm{g}$ adsorbent for a unit equilibrium concentration which is an approximate indicator of adsorption capacity. These constants can be evolved by linearising the above equation by adopting mathematical techniques ${ }^{38}$.

Table 3 Freundlich constants for the adsorption of Rhodamine-B at various particle sizes at $300 \mathrm{~K}$

\begin{tabular}{cccc}
\hline $\begin{array}{r}\text { Particle } \\
\text { Size (BSS Mesh) }\end{array}$ & $\mathrm{n} \times 10$ & $\mathrm{~K}_{\mathrm{F}} \times 10$ & $\mathrm{R}^{2}$ \\
\hline 250 & 0.5015 & 2.0906 & 0.8191 \\
150 & 1.2040 & 1.4675 & 0.0963 \\
100 & 0.2151 & 2.4958 & 0.4210 \\
\hline
\end{tabular}

Table 4 Adsorption kinetic data for dye removal with various particle sizes, equilibrium time for $120 \mathrm{mins}$ at $300 \mathrm{~K}$

\begin{tabular}{ccccccc}
\hline $\begin{array}{c}\text { Particle Size (BSS } \\
\text { mesh No.) }\end{array}$ & $\begin{array}{c}\text { Dye conc. } \\
(\mathrm{mg} / 100 \mathrm{ml})\end{array}$ & $\mathrm{q}_{\mathrm{e}}$ & $\begin{array}{c}\gamma \\
\mathrm{x} 10^{-5}\end{array}$ & $\mathrm{~K}_{\mathrm{ad}}$ & $\mathrm{K}_{\mathrm{P}}$ & $\begin{array}{c}\mathrm{D}_{\mathrm{P}} \\
\mathrm{X}^{-10}\end{array}$ \\
\hline \multirow{3}{*}{100} & 5 & 0.44 & 7.33 & 0.0093 & 0.029 & \\
& 10 & 0.84 & 7.00 & 0.0117 & 0.048 & 0.1344 \\
& 15 & 1.25 & 6.94 & 0.0186 & 0.088 & \\
\cline { 2 - 7 } 150 & 20 & 1.56 & 6.50 & 0.0087 & 0.085 & \\
& 5 & 0.45 & 7.50 & 0.007 & 0.025 & \\
& 10 & 0.85 & 7.08 & 0.010 & 0.047 & 5.9700 \\
& 15 & 1.27 & 1.06 & 0.008 & 0.071 & \\
& 20 & 1.60 & 6.67 & 0.009 & 0.087 & \\
& 5 & 0.46 & 7.66 & 0.006 & 0.025 & \\
& 10 & 0.87 & 7.25 & 0.010 & 0.048 & 2.151 \\
& 15 & 1.27 & 7.06 & 0.006 & 0.069 & \\
& 20 & 1.62 & 6.75 & 0.009 & 0.088 & \\
\hline
\end{tabular}

Table 5 Langmuir constants and thermodynamic parameters for Rhodamine-B adsorption with different temperatures and particle size

\begin{tabular}{cccccccccc}
\hline $\begin{array}{c}\text { Particle } \\
\text { Size }\end{array}$ & $\begin{array}{c}\text { Temp } \\
\mathrm{K}\end{array}$ & Slope & $\begin{array}{c}\text { Inter } \\
\text { cept }\end{array}$ & $\begin{array}{c}\mathrm{b} \\
(\mathrm{l} / \mathrm{mg})\end{array}$ & $\begin{array}{c}\mathrm{Q}_{2} \mathrm{x} 10 \\
(\mathrm{mg} / \mathrm{g})\end{array}$ & $\mathrm{R}_{\mathrm{L}}$ & $\Delta \mathrm{H}^{\circ}$ & $\Delta \mathrm{G}^{\circ}$ & $\Delta \mathrm{S}^{\circ}$ \\
\hline \multirow{2}{*}{100} & 300 & 2.3058 & 0.1811 & 12.732 & 0.4336 & 0.079 & 530.08 & -123.9 & 36.33 \\
& 318 & 1.9691 & 0.1470 & 13.395 & 0.5078 & 0.092 & & & \\
\multirow{2}{*}{150} & 300 & 2.1908 & 0.1558 & 14.061 & 0.4564 & 0.083 & 2860 & -96.88 & 164.29 \\
& 318 & 2.0487 & 0.1453 & 14.099 & 0.4880 & 0.089 & & & \\
\multirow{2}{*}{250} & 300 & 2.1791 & 0.1513 & 14.402 & 0.4589 & 0.084 & & & \\
& 318 & 1.8864 & 0.0919 & 20.527 & 0.5301 & 0.095 & & -320.6 & 226.48 \\
\hline
\end{tabular}


The $1 / \mathrm{n}$ is a measure of adsorption intensity. It was learnt that, If $\mathrm{n}=1$ then that the partition between the two phases was independent of the concentration. If the $1 / \mathrm{n}$ value is below one it indicates a normal adsorption. On the other hand $1 / \mathrm{n}$ being above one indicates cooperative adsorption ${ }^{39,40}$. It is generally stated that the value of ' $n$ ' that is in the range of 2 to 10 , represents good adsorption isotherm. It was also observed that the 'n' values of the adsorbent for the dye at ambient temperature, and at various particle sizes were found out and this value is from 2 to 10 , which confirmed that the activated carbon underwent a favourable for Freundlich isotherm. The experimental data were attempted to fit into Freundlich adsorption isotherms, and it was efficiently and most effectively fitted. It clearly indicated that the system followed Freundlich adsorption isotherm model and the adsorbent's surface under study were heterogeneous. The correlation coefficient was evolved with graphical techniques, and it was tabulated (Table 3).

These values exhibited some deviation from linearity, and tried to form curves. It was clearly indicated in the graphs under observations (Figure 6). The reason for this behavior was that the initial curve portion represented the formation of monolayer followed by intraparticle diffusion at later stages and final plateau portion indicate the saturation of adsorption process. It was summarized that the KHAC followed Freundlich adsorption isotherm model, the derived ' $n$ ' value for almost all dyes being in the value from 1 to 10 . The graphical studies showed that the small deviation from linearity, the mechanism of adsorption followed the formation of monolayer, intraparticle diffusion and saturation in a favorable pattern.

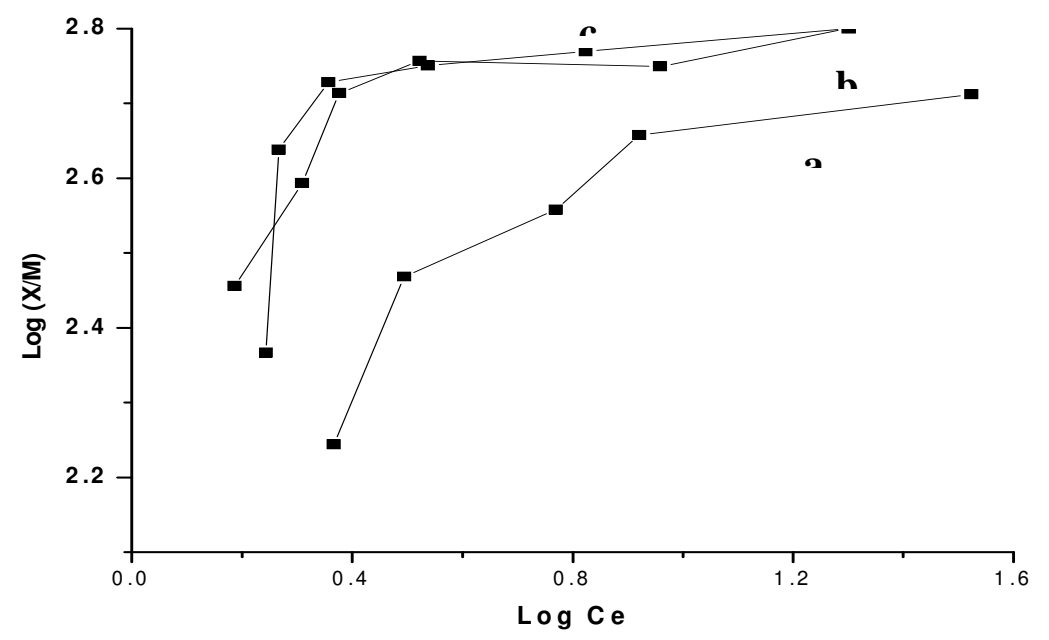

Figure 6. Freundlich isotherm curve for various particle sizes $\mathrm{a}-100 ; \mathrm{b}-150 ; \mathrm{c}-250 \mathrm{BSS}$ particle size

\section{Kinetics of Adsorption}

The adsorption kinetic study is quite significant in wastewater treatment as it describes the solute uptake rate, which in turn controls the residence time of adsorbate uptake at the solidsolution interface. Dosage study is an important parameter because it determines the capacity of adsorbent for a given initial concentration of the dye solution ${ }^{41}$. In this present investigation, the kinetics of the adsorption systems were studied by plotting the amount of 
dye adsorbed on the adsorbent with time for different adsorbent dosages at a constant initial concentration $(100 \mathrm{mg} / \mathrm{l})$, temperature $300 \mathrm{~K}$ and particle size $250,150,100 \mathrm{BSS}$ mesh numbers. In all the experiments, it was observed that with increase in adsorbent loading, the fraction of dye removal increased as shown in Figures 3-5.

From the nature of the curves, the amount of dye adsorbed on the adsorbent more or less remained constant. Moreover, the smoothness of the curves for dye adsorption showed that the process of adsorption was continuous and involved either monolayer formation on the adsorbent surface or monolayer coupled with other mechanisim predominantly with intra particle diffusion. Since the increase in active adsorption sites increased with adsorbent dosage, the amount of dye adsorbed increased with sorbent dosage. The large availability of adsorption sites with higher adsorption dosage has a positive effect on the initial rate of dye uptake. Similar type of trends in adsorption of dyes on different types of low cost adsorbents were reported ${ }^{41-43}$.

\section{Adsorption rate constant}

Determination of efficiency of adsorption process requires a thorough understanding of kinetics of uptake of adsorbate by adsorbent or the time dependence of the concentration distribution of the solute in both bulk solution and solid adsorbent and identification of rate determining step.

In order to investigate the mechanism of sorption and potential rate controlling steps such as mass transport and chemical reaction processes, the Lagergren kinetic model (Figures 7-9) known as pseudo-first order equation, has been used to test the experimental data.

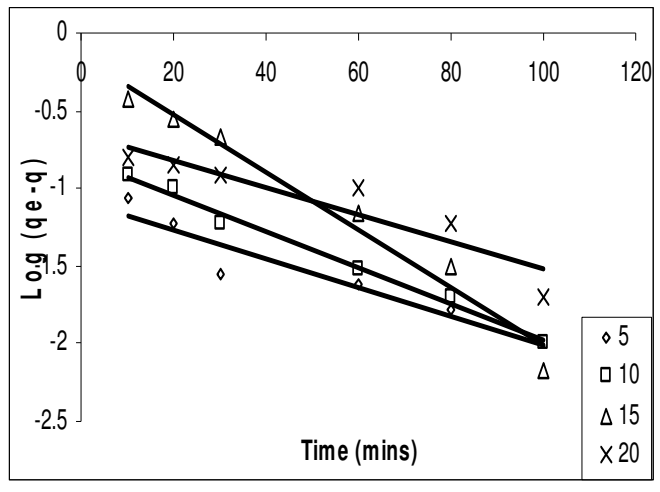

Figure 7. Lagergren plot for removal of Rhodamine-B with particle size 100BSS at $300 \mathrm{~K}$

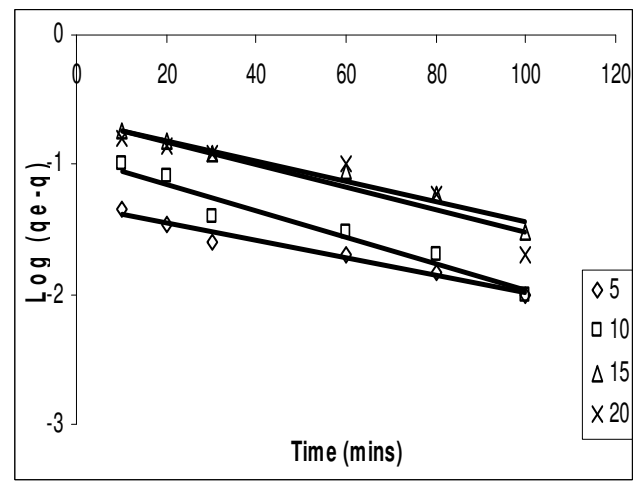

Figure 8. Lagergren plot for removal of Rhodamine-B with particle size 150BSS at $300 \mathrm{~K}$

\section{Pseudo - First Order Equation}

The pseudo-first order equation of Lagergren is generally expressed as follows, $\mathrm{dq} / \mathrm{dt}=\mathrm{K}_{\mathrm{ad}}$ $\left(\mathrm{q}_{\mathrm{e}}-\mathrm{q}_{\mathrm{t}}\right.$ ); where $\mathrm{q}_{\mathrm{e}}$ and $\mathrm{q}_{\mathrm{t}}$ are the sorption capacity at equilibrium and sorption capacity at time and $\mathrm{K}_{\mathrm{ad}}$ is the rate constant of pseudo - first order sorption (1/min). After integration and applying boundary condition $\mathrm{t}=0$ to $\mathrm{t}=\mathrm{t}$ and $\mathrm{q}=0$ to $\mathrm{q}=\mathrm{q}_{\mathrm{t}}$, the integrated form becomes, $\log \left(\mathrm{q}_{\mathrm{e}}-\mathrm{q}_{\mathrm{t}}\right)=\log \mathrm{q}_{\mathrm{e}}-\left[\mathrm{K}_{\mathrm{ad}} / 2.303\right] \mathrm{t}$. 
Data for Lagergren plots of dyes were presented in Figures 7-9. The linear plots of log $\left(q_{e}-q_{t}\right)$ Vs t showed that adsorption followed the pseudo first order rate expression given by

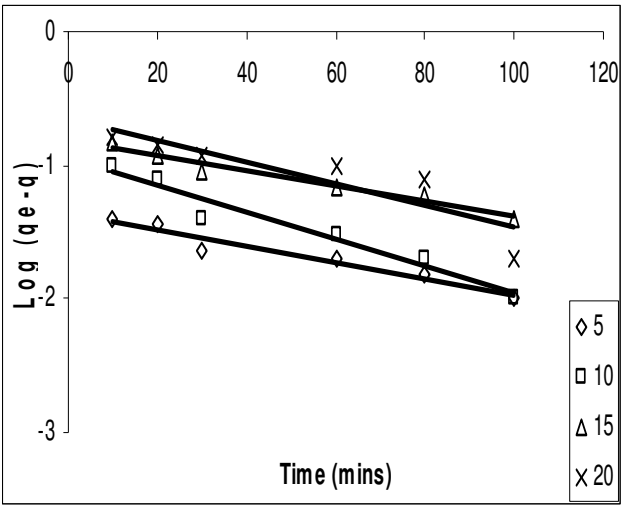

Figure 9. Lagergren plot for removal of Rhodamine-B with particle size 250BSS at $300 \mathrm{~K}$

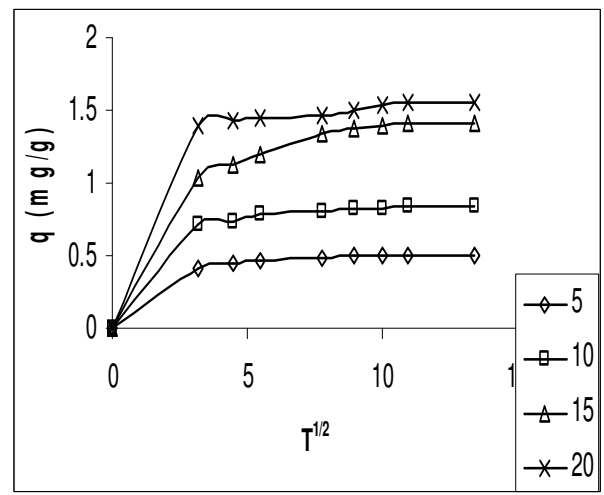

Figure 10. Intraparticle diffusion plot for the adsorption of Rhodamine-B on 100BSS particle size at $300 \mathrm{~K}$

Lagergren. The $\mathrm{K}_{\mathrm{ad}}$ values for Rhodamine - B was calculated from the slope of linear plots. The rate constants for adsorption $(1 / \mathrm{min})$ of dye at ambient temperature of different particle size are presented in the Figures. From these observations, the KHAC follows Lagergren pseudo first order kinetics. Similar patterns of results were reported earlier ${ }^{44,45}$.

\section{Diffusion Studies}

Pore Diffusion Coefficient $\left(D_{P}\right)$

The pore diffusion coefficient values fall between $10^{-11}$ to $10^{-13}$ and the process is said to be controlled due to intraparticle diffusion coefficient ${ }^{26}$. Similarly, if the external diffusion coefficient value falls between $10^{-5}$ to $10^{-8}$, then the process is said to follow external mass transfer ${ }^{46,47}$. Based upon the assumption of Helfferich that the geometry of the adsorbent particles is spherical in nature ${ }^{48}$. The studies of Webber proves that the adsorption kinetics with pore diffusion coefficient are inter related and the rate determining step is based upon pore diffusion coefficient ${ }^{34,49}$.

Pore Diffusion Coefficient $\mathrm{D}_{\mathrm{P}}=0.03\left(\mathrm{r}_{0}^{2}\right) / \mathrm{t}_{1 / 2}$

Where, $t_{1 / 2}$ - Time for half-change (mins)

$\mathrm{r}_{0}$ - Radius of adsorbent $(\mathrm{cm})$

The values of pore diffusion coefficients were calculated on the particles size for the dye and these inferences were compared with the results and it was inferred that pore diffusion was not the rate limiting step ${ }^{50}$. Based upon different ideas available in literature, it is possible to determine the nature of adsorption process with reference to the pore diffusion coefficient. If the values fall between $10^{-11}$ to $10^{-13}\left(\mathrm{~cm}^{2} / \mathrm{s}\right)$ and the process is said to be controlled due to intraparticle diffusion coefficient ${ }^{26}$, but the dye system under study showed the value in the range of $10^{-8}$ to $10^{-10}\left(\mathrm{~cm}^{2} / \mathrm{s}\right)$. These values were presented in the Table 4. 


\section{Intraparticle Diffusion $(q)$}

The intraparticle diffusion rate constant can be given as follows, $q=K_{p} T^{1 / 2} ; K_{p}$ values for the adsorption of the dye are presented in the Table 4 . The rate constant for intraparticle diffusion $\mathrm{K}_{\mathrm{p}}$ was calculated from the slope of the linear equation Figures 10-12.

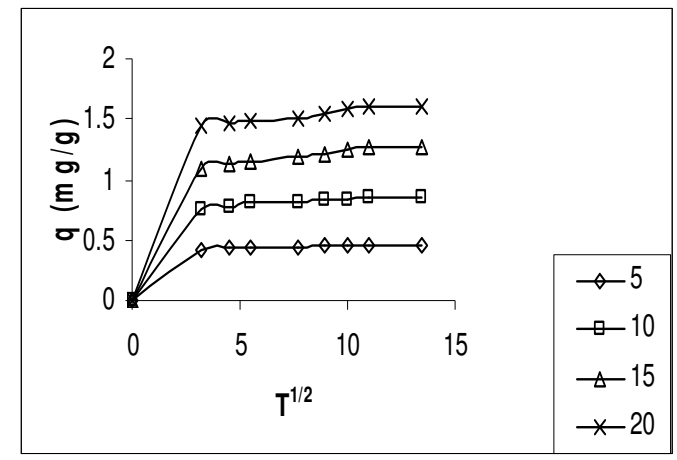

Figure 11. Intraparticle diffusion plot for the adsorption of Rhodamine-B on 150BSS particle size at $300 \mathrm{~K}$

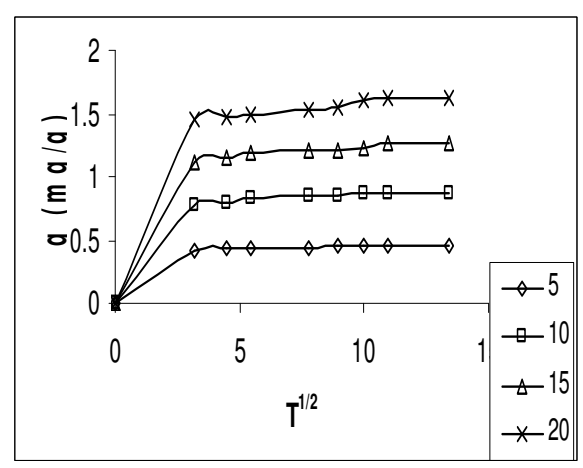

Figure 12. Intraparticle diffusion plot for the adsorption of Rhodamine-B on 250BSS particle size at $300 \mathrm{~K}$

From these figures it was found that the initial sharp portion with subsequent linearity indicated that more than one mode of sorption mechanism was in operation. The first sharp portion may be due to external surface adsorption stage are instantaneous adsorption. The second gradual linear portion may be due to gradual intraparticle diffusion stage. The third linear may be due to final equilibrium stage ${ }^{42}$.

The values of $\mathrm{K}_{\mathrm{p}}$ generally increased with the increase in dye concentration and it can be related to concentration diffusion. Similar results were reported for metal ion adsorption onto activated carbon cloths ${ }^{43,51}$.

\section{Initial adsorption coefficient $(\gamma)$}

The initial adsorption coefficient equation can be given as.

$\gamma=(\mathrm{dC} / \mathrm{dt}) \mathrm{t}_{\mathrm{o}} \times \mathrm{V} / \mathrm{M} \mathrm{C}_{\mathrm{o}}$

Where,

$$
\begin{aligned}
\mathrm{dC} & =\mathrm{C}_{\mathrm{e}} \text { at equilibrium time } \\
\mathrm{dt} & =\text { Equilibrium time } \\
\mathrm{V} & =\text { Volume of solution } \\
\mathrm{M} & =\text { Mass of carbon } \\
\mathrm{C}_{\mathrm{o}} & =\text { Initial concentration }(\mathrm{mg} / \mathrm{l})
\end{aligned}
$$

The values for the adsorption coefficient of the dyes are presented in the Table 4 . The initial adsorption coefficients increased with increase in initial dye concentration and therefore it is concentration dependent. From the results, an overall examination of effect of dye concentration on rate constant $\mathrm{K}_{\mathrm{ad}}$ describe the mechanism of adsorption takes place. In the cases of strict surface adsorption, a variation of rate should be proportional to the concentration. The relationship between initial solute concentration and the rate of 
adsorption was not linear. This was due to the limitation caused by pore diffusion of the adsorption. It is clearly indicated in the Table 4. It was concluded that pore diffusion also limited the overall rate of adsorption.

\section{Effect of $p H$}

The experiments carried out at different $p \mathrm{H}$ show that there was no change in the percent removal of dye over the entire $\mathrm{pH}$ range, except that there was $4 \%$ decrease when the $\mathrm{pH}$ was lowered from 3 to 1 . This indicates the strong force of interaction between the dye and KHAC that either $\mathrm{H}^{+}$or $\mathrm{OH}^{-}$ions could not influence the adsorption capacity. In other words, the adsorption of Rhodamine-B dye on KHAC does not involve ion exchange mechanism. If the adsorption would have occurred through ion exchange mechanism there should have been an influence on the dye adsorption while varying the $\mathrm{pH}$. This observation is in line (Figures 3-5) and high positive $\Delta \mathrm{H}^{\circ}$ value obtained, which indicates irreversible adsorption probably due to non-polar interactions.

\section{Desorption studies}

Desorption studies help to elucidate the nature of adsorption and recycling of the spent adsorbent and the dye. If the adsorbed dye can be desorbed using neutral $\mathrm{pH}$ water, then the attachment of the dye on the adsorbent is by weak bonds. If sulphuric acid or alkaline water can desorbs the dye, then the adsorption is by ion exchange. If organic acids, like acetic acid can desorb the dye, then the dye is held by the adsorbent through chemisorption. Neutral $p \mathrm{H}$ water, $1 \mathrm{M}$ sulphuric acid and $1 \mathrm{M}$ sodium hydroxide did not show any desorption of the dye. However, $10 \%$ acetic acid (v/v) and 50\% acetic acid (v/v) solubilized 9 and $38 \%$ of Rhodamine-B, respectively, from the dye adsorbed carbon. The non-reversibility of adsorbed dye in mineral acid or base is in agreement with the $p \mathrm{H}$ independent results obtained. Desorption of dye in acetic acid (organic medium) indicates that the Rhodamine-B are adsorbed onto KHAC carbon through activated chemisorption mechanism.

\section{Conclusion}

Carbon prepared from waste Kapok hull was found to be cost effective in removing Rhodamine dye-B dye from aqueous solution. The adsorption is faster and the rate is mainly controlled by intraparticle diffusion. The surface morphology studies using SEM proves that, it contains more pores that leads to develop more adsorption sites. The XRD pattern confirms the amorphous nature of the adsorbent.

Since Rhodamine-B is a basic dye, it is expected that the variation in $\mathrm{pH}$ will influence the adsorption but the experiments carried out at different $\mathrm{pH}$ show that there was no change in the percent removal of dye over the entire $\mathrm{pH}$ range, except that there was $4 \%$ decrease when the $\mathrm{pH}$ was lowered from 3 to 1 . This indicates the strong force of interaction between the dye and KHAC that either $\mathrm{H}^{+}$or $\mathrm{OH}^{-}$ions could not influence the adsorption capacity. The adsorption of Rhodamine-B dye on KHAC does not involve ion exchange mechanism. It is supported by high positive $\Delta \mathrm{H}^{\mathrm{o}}$ values obtained, which indicates irreversible adsorption probably due to non-polar interactions.

It is evident from the studies that the use of chemically modified Kapok hull activated carbon for the removal of Rhodamine-B dye is technically feasible and irreversible adsorption and not influenced by acidic or basic nature of dye. 
It is evident that KHAC is eco-friendly and economically feasible for the treatment of dye house wastewater before subjecting to reverse osmosis, there by increase the life expectancy of valuable resins used in this system.

\section{References}

1. McKay G, Waste colour removal from textile effluents, Amer. Dyestuff Rep., 1979, 68, 29-34.

2. Jorgensen S E, Industrial waste water management studies in Environmental Science, Vol.5, Elsevier Scientific Publishing Company, Amsterdam, Oxford, New York, 1979.

3. Kiff R J, General inorganic effluents: In surveys in industrial waste water treatment-Manufacturing and chemical industries, Eds: Barnes Forste, D C F and Hrudey, S E. 3, Longman, New York, 1987

4. Judkins Jr, J F, Textile wastes, Cont J. Wat. Pollute. Fed., 1982, 57, 702.

5. Datya Keshav V, Vaidya, Chemical processing of synthetic fibres and blends, John wiley \& sons, New York, 1984, 535.

6. Namboodri C G, Perkins W S and Wlash W K, Decolorizing dyes with chlorine and Ozone: Part 11 Amer. Dyestuff Rep, 1994, 4, 17.

7. Liakou S, Kornaros M and Lyberatos G, Wat. Sci. Technol., 1997, 36, 155.

8. Uygur A and Kok E, JSDC., 1999, 115, 351.

9. Ince N H and Gonene D T, Environ. Technol., 1997, 28, 179.

10. Polard S J T, Fowler G D, Sollar C J and Poerry R, A review Sci. Total Environ.,1992, 16, 31.

11. Asfour H M, Nassar M M, Fadali O A, EI M S, Geundi, J. Chem. Technol. Biotechnol., 1985, 35 A, 28.

12. Nawar S S and Doma H S, The Sci. Tot. Environ., 1989, 79, 271.

13. Low K.S and Lee C K, Pertanica, J. Sci. Technol.,1990, 13, 221.

14. Gupta G S, Prasad G and Singh V N, Water Research, 1990, 24, 45.

15. Namasivayam C and Chandrasekaran K, J. Indian. Asso. Environ. Mgt., 1991, 18, 93.

16. Namasivayam C and Kanchana N, Chemosphere, 1992, 21, 1691.

17. Namasivayam C and Yamuna R T, Amer. Dye stuff Rep., 1994, 83, 22.

18. Deo N and Ali M., Indian J. Environ. Prot., 1993, 13, 496.

19. Namasivayam C and Kadirvelu K, Bioresource Technology, 1994, 48, 79.

20. Juang Rvey-Shin, Ru-Ling Tseng, Feng - Chin Wa, Shwu-Hwa lww, J. Chem. Technol. Biotechnol., 1997, 70, 391.

21. Malik U, Taneja, Utilizing fly ash for color removal of dye effluents, America dye stuff reporter, 1994, 20.

22. Namasivayam C and Arasi D J S E, Chemosphere, 1997, 34, 410.

23. Venkatamohan S, Mamatha V V S and Karthikeyan J, Fresenius Environ Bull.,1998,7, 51.

24. Morais L C, Goncalves E P, Vascobcelos L T and Gonzalezbeca C G, Environmental Technol., 2000, 21, 577.

25. Rajeswari Sivaraj, Sivakumar,S., Senthilkumar, P, V.Subburam, Bio-resour. Technol., 2001, 80, 233.

26. Stephan Inbaraj B and Sulochana N, Indian J. Chemi. Technol., 2002, 9, 201.

27. Rajeswari Sivaraj and V.Subburam, Bio-resour. Technol., 2002, 85, 205. 
28. Rajavel G, Ananthanarayan C, Prabhakar L D and Palanivel, Indian J. Environ. Health, 2003, 45, 195.

29. Janos P, Buchtova H and Ryznarova M, Water Res.,2003, 37, 4938.

30. Malik P K, J. Hazard Matter, 2004, 113, 81.

31. Namane A, Mekarzia A, Benrachedi K, Belhaneche Bensemra N and Hellal A, $J$. Hazard Matter, 2005, 119, 189.

32. Ozacar M and Sengil I A, Bioresour. Technol., 2005, 96, 791.

33. Khattri S D and Singh M K, Ind.Chem.Technol.,1999, 6,112.

34. Weber T N and Chakravarti R K, J .Am. Inst .Chem. Engg., 1974, 20, 228.

35. Gupta V K, Ali I, Suhas and Mohan D, J Colloid Interface Sci.,2003, 265, 257.

36. Ho Y S, Porter J F and McKay G, Water Air and Soil Pollution., 2002, 141, 1.

37. Albanis T A , Hela D G, Sakell Arides J M and Danis T G, Global Nest: the Int. J., 2000, 2(3), 237.

38. Voudrias E, Fytianosand F and Bozani E, The Int. J. 2002, 4(1), 75.

39. Mohan S and Karthikeyan J, Environ.Pollut., 1997, 97, 183.

40. Atkins P, Physical chemistry, Oxford University press, Oxford, U.K., 1970

41. Lakshminarayanan Rao K C and Krishniah K, Indian J. Chem. Technol.,1994,1, 13.

42. McKay G, Otterburn, M S and Sweeny A G, Water Res., 1980, 14, 15.

43. Namita Deo and Manzoor Ali., Ind.J.Env.Prot., 1993, 13, 570.

44. Webber W J, In principal and application of water chemistry, edited by Faust S D \& Hunter, $J$ V, Wiley, New York, 1967

45. Bhatnagar A and Jain A K, J. Colloid Interface Sci., 2005, 281(1), 49.

46. Furusuwa $\mathrm{T}$ and Smith $\mathrm{J} \mathrm{M}$, Intraparticle mass transport in slurries by dynamic adsorption studies. AIChE, 1974, 20, 88.

47. Khare S K, Pandey K K, Srivastava R M and Singh V N, J. Chem. Techcol. Biotechnol., 1987, 35, 99.

48. Helfferich, F, Ion Exchange. New York: McGraw-Hill, 1962

49. Lee V K, Porter J F and McKay G, J .Cem Technology Bio Technol., 2003, 78(12), 1281.

50. Wu F, Tseng R and Juang R, J. Hazard Mater., 1999, 69, 287.

51. Kadirvelu K, Karthika C, Venilamani N and Pattabhi S, Chemosphere 2005, 60,1009. 


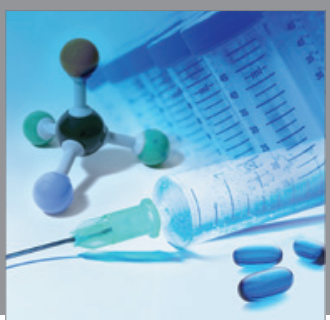

International Journal of

Medicinal Chemistry

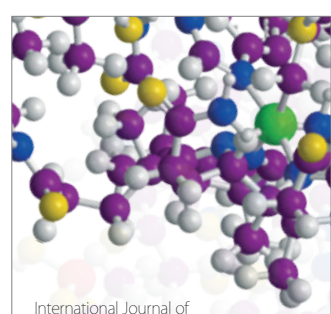

Carbohydrate Chemistry

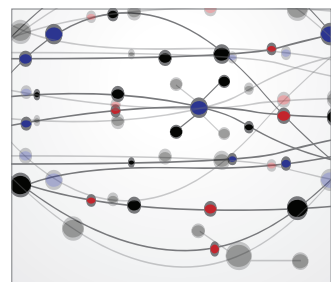

The Scientific World Journal
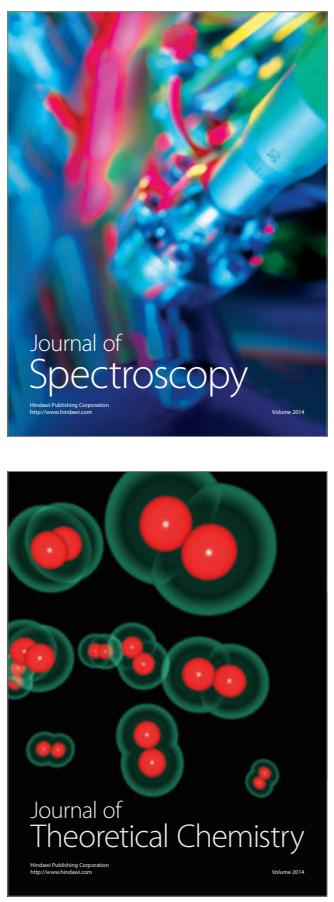
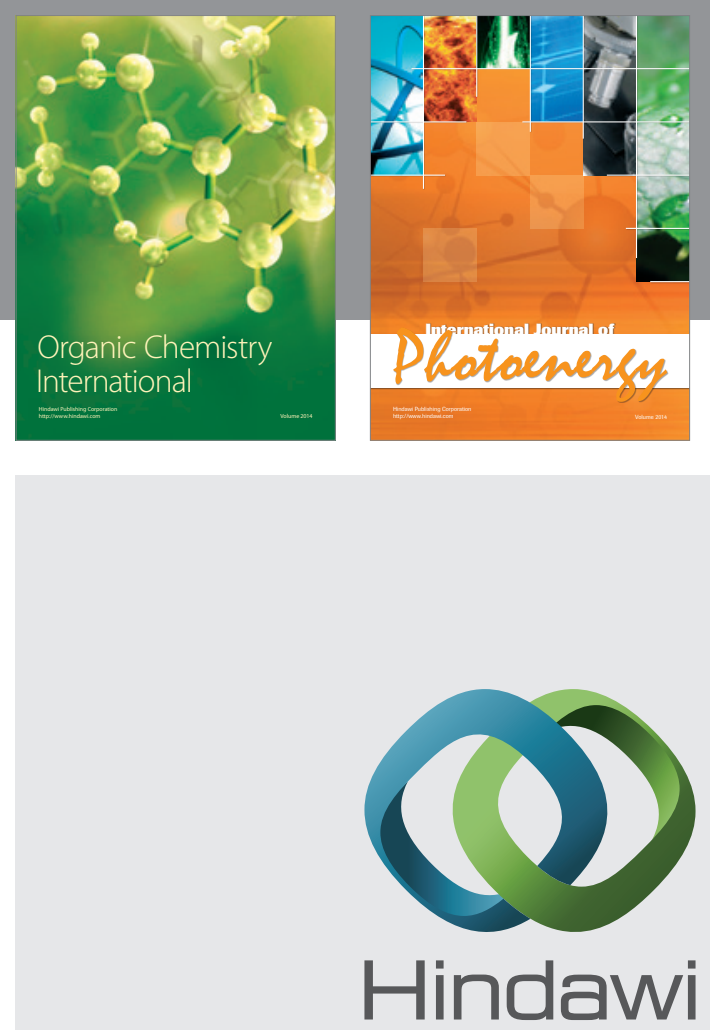

Submit your manuscripts at

http://www.hindawi.com
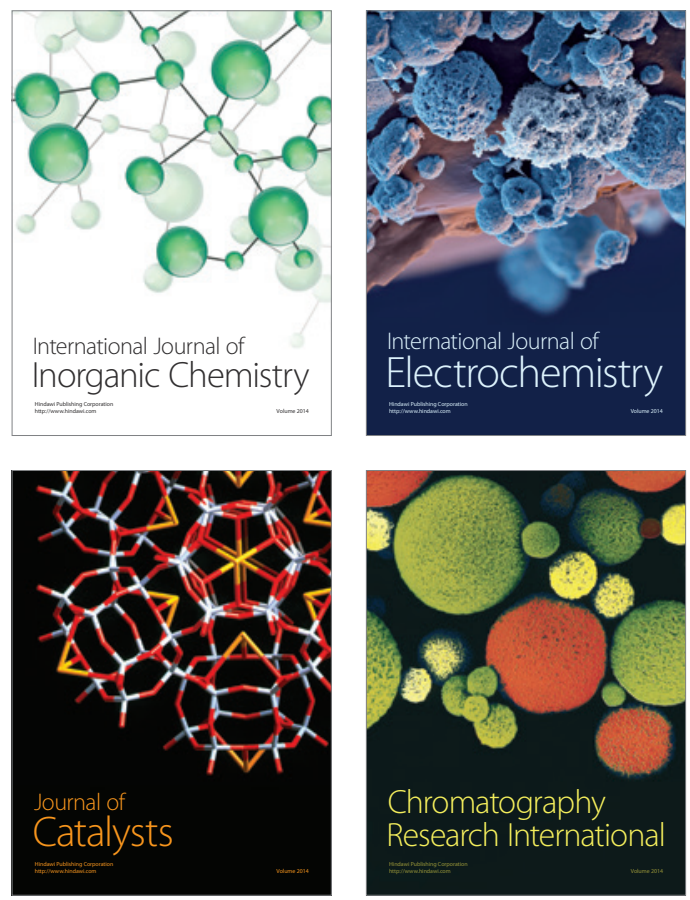
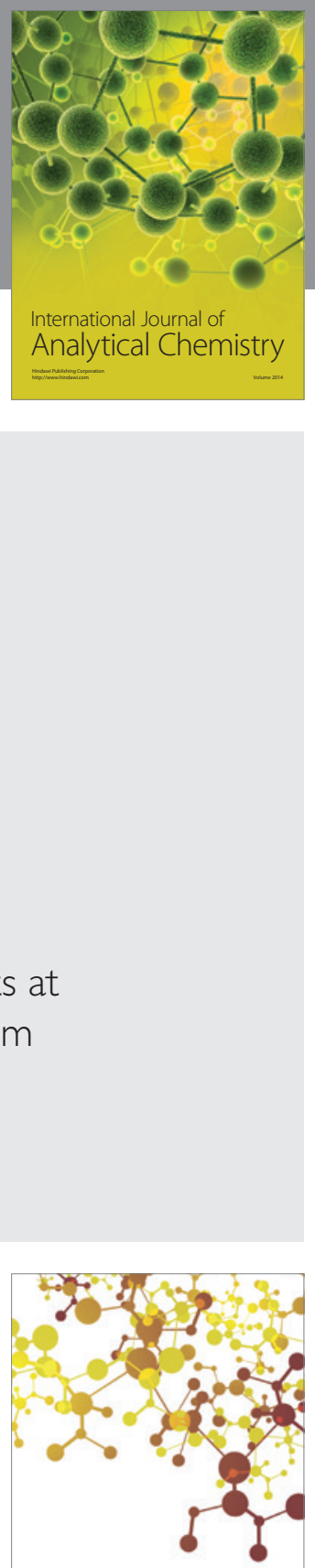

Journal of

Applied Chemistry
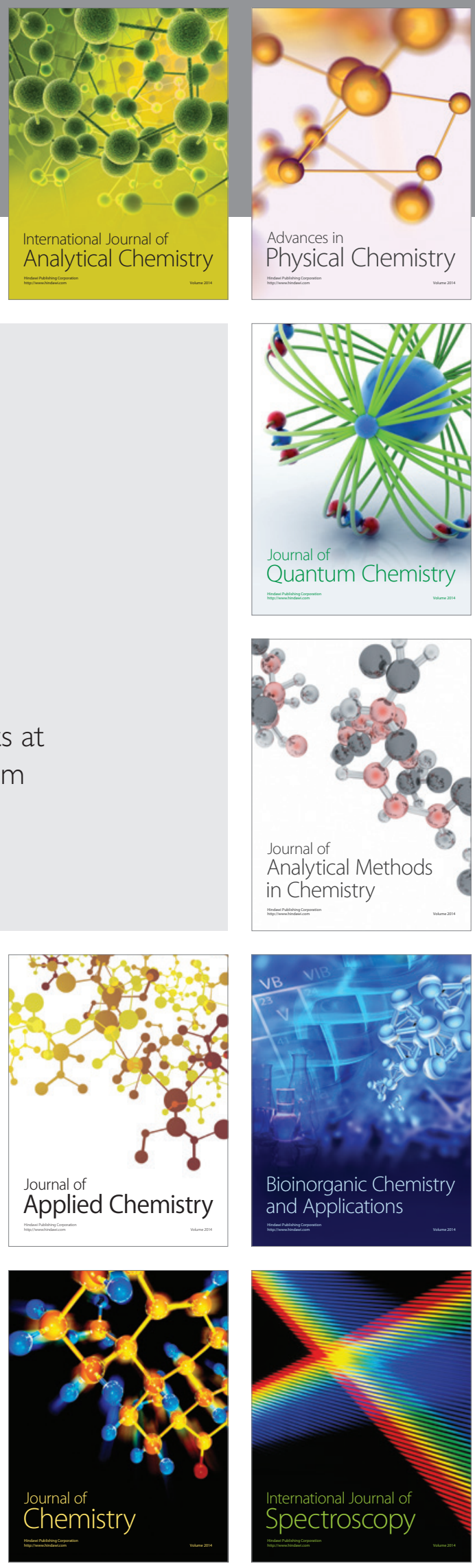